\title{
An Agent-Based Modeling Approach to Investigating the Impact of Water
}

\section{Demand Management}

\author{
Yi Xiao ${ }^{1}$, Liping Fang ${ }^{2}$, and Keith W. Hipel, Hon.D.WRE, F.ASCE ${ }^{3}$
}

Abstract: An agent-based modeling approach is proposed to assess water users' behavior for water demand management (WDM) in a river basin. In this procedure, each agent controls its own strategy regarding whether to conserve or consume more water in order to achieve a better economic return based on an initial allocation scheme. The effects of agents' behaviors on their own economic returns and the aggregated impacts of individual behavior on the system are investigated. A positive incentive given to water conservers encourages agents to implement WDM strategies, which in turn improve water use efficiency. A case study using this new agentbased approach reveals that agricultural users are the main contributors to water conservation. Compensation given to water conservers more than covers the benefit loss from less water consumption, while other users gain benefits from the use of the conserved water. The results also indicate that the implementation of WDM strategies is beneficial for the overall system from both economic and ecological perspectives.

Keywords: Water demand management; Agent-based modeling; Optimization; Incentive

\footnotetext{
${ }^{1}$ Postdoctoral Fellow, Department of Systems Design Engineering, University of Waterloo, Waterloo, Ontario, Canada N2L 3G1. E-mail: yi.xiao@uwaterloo.ca

${ }^{2}$ Professor, Department of Mechanical and Industrial Engineering, Ryerson University, Toronto, Ontario, Canada M5B 2K3; and Adjunct Professor, Department of Systems Design Engineering, University of Waterloo, Waterloo, Ontario, Canada N2L 3G1 (corresponding author). E-mail: lfang@ryerson.ca

${ }^{3}$ University Professor, Department of Systems Design Engineering, University of Waterloo, Waterloo, Ontario, Canada N2L 3G1; Senior Fellow, Centre for International Governance Innovation, Waterloo, Ontario, Canada N2L 6C2; and Fellow, Balsillie School of International Affairs, Waterloo, Ontario, Canada N2L 6C2. E-mail: kwhipel@uwaterloo.ca
} 


\section{Introduction}

Available water supply is limited and water demand in almost all sectors is projected to increase greatly in the near future (Leflaive et al. 2012); consequently, the use of limited water resources to satisfy the growing need has become a critical issue (Gleick 2003; Brooks and Brandes 2011, WWAP 2015). One of the traditional solutions is to implement inter-basin water transfers to increase water availability in a region in order to meet the growing demand. This is normally referred to as supply-oriented management. Another solution is to encourage more efficient and productive use of the available water. Water demand management (WDM) emerged from this latter idea, and has become an essential complement to supply-oriented management. In addition, three important factors have accelerated the development of WDM. The first is the increase in water conflicts caused by water scarcity, as measured by both frequency and severity (Wolf 2002; Gleick and Heberger 2014). The second is the great potential to use water more productively; for example, a more widespread adoption of advanced technologies and implementation of welldesigned policies and operations could significantly improve water productivity. The third factor is the impact of climate change on water availability, which further stresses the necessity of management on the demand side (Olmstead 2014).

In general, WDM aims to improve the efficiency and productivity of water use by encouraging changes in user behavior regarding water use through a series of cost-effective structural and/or non-structural measures. Structural measures refer to any physical construction used to conserve water, such as the installment of high-efficiency appliances like low-flush toilets. Non-structural measures stand for any measures not directly involving physical structures, such as using economic instruments or educational programs to promote water use efficiency. This improvement of efficiency and productivity can be viewed from two aspects: (1) to 
accomplish more tasks with the currently available water; and (2) to reduce water consumption from the current level as much as possible to accomplish the same task.

WDM can be considered from different perspectives, such as engineering or law, and different scales, like local or national (Tate 1989; Renzetti 2002; Savenjie and van der Zaag 2002; Brooks 2006). Various topics in WDM, ranging from technical to economic and legal, have been broadly studied in the literature (Baumann et al. 1997; Savenije and Van Der Zaag 2002; Bulter and Memon 2006; Scheierling et al. 2006; Olmstead and Stavins 2009; Kindler 2010; Kampragou et al. 2011; Araral and Wang 2013; Smith et al. 2015). Many investigations have suggested that WDM is an issue more of perception than of technology (Mass 2003). The technological capacity for WDM is already well-developed and the conservation potential could be significant (Blanke et al. 2007; Christian-Smith et al. 2012). For instance, in an investigation of water-saving technologies and their adoption rates in agriculture in northern China, reported by Blanke et al. (2007), the authors found that although there are a number of existing technologies, their adoption rates are quite low. One of the main reasons for this is that farmers themselves make the majority of investments in technologies, thereby having poor motivation to adopt new technologies.

People normally do not voluntarily adopt advanced water-saving technologies unless it is beneficial to do so. Sometimes external incentives are required to entice users to change their water use behavior, especially for users in sectors that possess great potential for water conservation. It is believed that every user has the potential to enhance its water use efficiency as long as proper incentives are offered. The problems of what incentives are needed and how water users respond to the incentives under the context of WDM need to be investigated. 
In the face of incentives, every water user possesses a different capability and willingness to implement WDM strategies. Moreover, a particular user's actions on WDM may have impacts on other users as well as the overall system. Therefore, agent-based modeling (ABM) techniques are well-suited for addressing these characteristics of WDM problems because: (1) they are individual-driven modeling approaches, in which each user has its own behavioral rules, and can therefore handle the heterogeneity of capability and willingness; (2) they are adaptive, because each user can change its behavior according to information received from other users and the environment. Furthermore, ABM techniques do not require perfect information exchange. In other words, users do not need to share information completely with others.

Water resources systems are normally considered as a complex system in which heterogeneous users act based on different value systems and objectives (Pahl-Wostl 2002; 2003). Water resources management, especially WDM, is a relatively new field for ABM. However, because of the capability of ABM to investigate dynamic complex systems, a number of studies on the application of ABM can be found. For example, Chu et al. (2009) utilized ABM techniques to evaluate the responses of different users in Beijing, China, in the face of a series of water supply and demand management policies such as offering financial rebates for replacing low-efficiency appliances with high-efficiency ones. Kanta and Zechman (2013) investigated the effectiveness of water conservation-based strategies using $\mathrm{ABM}$ methods in which the users' water demand level is influenced by policy makers, who select water conservation strategies, and by other users' choices. Giacomoni et al. (2013) examined dynamic interactions among water use, land use, and urbanization progress within a complex adaptive system framework in which $\mathrm{ABM}$ is utilized to simulate the water use behavior of each household. Other interesting research topics using ABM techniques include water demand estimation (Athanasiadis et al. 2005), water 
sharing problems (Yang et al. 2009; 2012; Guiliani and Castelletti 2013; Giuliani et al. 2014), and common pool resources management (Schlüter and Pahl-Wostl 2007; Bristow et al. 2014). Berglund (2015) provides a comprehensive review of the employment of $\mathrm{ABM}$ in water resources management.

Most ABM studies adopt simple decision rules like logic conditions or random choices to update agents' behavior. There has been some work done on the adoption of complex decision rules in the ABM framework. For example, Yang et al. $(2009 ; 2012)$ utilized decentralized optimization methods to investigate how each agent acts and interacts with others in order to maximize its own benefits in a water sharing problem. Bristow et al. (2014) introduced a comprehensive decision-making tool called Graph Model for Conflict Resolution (GMCR) as the interaction mechanism among agents in a common pool resources conflict. In this paper, decentralized optimization methods are utilized as the decision rules within an agent-based model to investigate the changes of water users' behavior in the context of WDM, and their corresponding impacts on individual users and the system as a whole.

This work possesses the following novelties: (1) The proposed model is a more general framework for WDM in comparison to the existing research, which normally has a site-specific dependence. In most existing studies, one or several WDM strategies are first specified, and then evaluated for effectiveness. However, the approach developed in this paper focuses more on the amount of water conserved than on which strategy to adopt, and thereby is more independent of specific situations. (2) WDM is studied from a decentralized perspective, which considers the willingness and capability of different users in different ways. An individual optimization problem is constructed to help each agent make decisions. The involvement of individual decisions can greatly promote public participation and acceptance. (3) WDM is considered in the 
context of basin-wide planning and management, thereby enabling the integration of demandside and supply-side management. Therefore, water efficiency and productivity are emphasized.

\section{Problem Statement}

Following the research of Mohamed and Savenije (2000), each type of WDM measure is categorized according to positive and negative incentives. Positive incentives normally imply money being given to water users, such as subsidies for adopting new technologies, while negative incentives generally mean money being taken from users, such as water prices or taxes. Both positive and negative incentives have their advantages and drawbacks, and should be selected according to specific circumstances, or sometimes combined. However, because positive incentives are usually more acceptable to users, participation rate and compliance level for the WDM measures are expected to be improved, thereby achieving better effectiveness. As a result, positive incentives receive special attention in this paper.

A river basin is chosen as a study unit in this work because there are various sectors of water users in a basin, and some sectors are expected to require more water and are willing to pay a charge to obtain it. In a basin, several types of water users, such as agricultural production, urban development, industrial use and ecological maintenance, share limited water resources. The competition for water is becoming much more intense as a result of exponentially growing water demands and an increasing awareness of environmental conservation. Encouraging water flow towards higher-value uses from lower-value ones constitutes a possible solution for improving water productivity. However, improving water productivity is not the only objective, nor even the highest priority, of WDM. Social equity must be taken into account for any implementation of WDM strategies, and existing legal systems or multilateral agreements must be respected. For example, in a region with a prior water rights system (Wang et al. 2007), even lower-value uses 
could have the right to withdraw most of the water, which may result in having a water deficit to some higher-value uses during water shortage periods. Due to this consideration, an initial allocation step, emphasizing fair sharing of water resources according to existing water rights systems, is followed prior to the implementation of WDM. Approaches that are applicable under different water rights systems proposed by Wang et al. (2007) are utilized here for obtaining initial allocation schemes. Therefore, the problems of how each water user in a river basin decides whether to conserve or consume more water in order to achieve a better economic return based on an initial allocation scheme, and how users' decisions impact individual users and the system as a whole, are investigated in this paper.

\section{Methodology}

A typical agent-based model possesses four main components (Macal and North 2010; Bristow et al. 2014): (1) a set of agents in which each agent has unique attributes; (2) an environment that agents can interact with as well as other agents; (3) methods that agents use to update their attributes; and (4) an interaction mechanism that controls when and how to interact, and with whom.

To formulate the agent-based model as well as the initial allocation step, some preliminary notation from Wang et al. (2007) is necessarily introduced. In general, a node-link network is abstracted to represent a basin, in which a node implies a physical component of interest such as inflow, junction, reservoir, or demand site, and a link stands for natural or man-made water conduits connecting different nodes.

Let $G(K, L)$ be the directed network of a basin, where $K=\left\{k_{1}, k_{2}, \ldots, k_{m}\right\}$ is the set of nodes, and $L=\left\{\left(k_{1}, k_{2}\right): k_{1}, k_{2} \in K\right.$ and $\left.k_{1} \neq k_{2}\right\}$ is the set of links in which $\left(k_{1}, k_{2}\right)$ stands for a water 
conduit connecting two nodes $k_{1}$ and $k_{2}$ (Wang et al. 2007). Water users that are assigned as agents are defined by the set $N=\{1,2, \ldots, i, \ldots, n\}$. Since set $K$ represents all possible nodes such as reservoirs or demand sites and set $N$ refers to some nodes defined as agents like demand sites, set $N$ is a subset of $K$. In addition, $T=\{1,2, \ldots, t, \ldots, \tau\}$ stands for the time period for planning.

\section{Agents and Their Decision Rules}

In a basin-wide agent-based model for WDM, each water user can be defined as a computational agent, structured as in Table A1 in the Appendix. All of the water users in a basin are categorized into two main types of agent - general and ecosystem - which correspond to two main types of water uses: consumptive and non-consumptive. General agents refer to consumptive uses, which normally consist of agricultural, municipal, and industrial uses. Since consumptive uses are the focus of WDM, these agents receive particular attention in the agent-based model in this paper. In general, these agents are under the control of certain users or user groups; therefore, their levels of water consumption can be actively updated. Non-consumptive uses, like reservoirs and instream flow requirements, are commonly dependent on the water usage of consumptive uses (general agents). For a given water supply, consumptive uses diverting more water normally make less water available for non-consumptive uses, and vice versa. Among non-consumptive uses, instream flow requirements are assessed along with general agents, and are labeled as ecosystem agents, whereas reservoirs are not assessed. In fact, ecosystem agents could also have the same two attributes: water consumption and economic net benefit. However, the economic value of the ecosystem agents is normally intangible and may require special valuation methods. Furthermore, for an ecosystem agent, more water typically means better performance; instream 
water availability is a more direct indicator than economic value. As a result, only the water consumption attribute is considered for ecosystem agents.

Two main attributes are assigned to each general agent: water consumption and net benefit function. Water consumption means how much water an agent uses, for which an initial value is set to the initial allocation for each agent (initial allocations for the case study in this paper are listed in Table S5 in the Supplemental Data). The initial allocation schemes are obtained using a priority-based maximal multi-period network flow approach proposed by Wang et al. (2007). In the agent-based model, each agent updates its level of water consumption based on an initial level of water consumption. When the level of water consumption is less than the initial level, the agent is practicing water conservation. Conversely, an agent's level of water consumption may be greater than the initial level. A third case is if an agent neither conserves nor consumes more water, but retains its initial level of water consumption.

A net benefit function is used to denote the relationship between water utilization and its output as represented by economic net benefit. How much economic net benefit an agent generates can be estimated by using different forms, since different agents have different capabilities. In this paper, the net benefit functions for agricultural agents are represented by using the quadratic form, in which the coefficients are derived from a regression analysis model and are provided in Tables S8 to S10 in the Supplemental Data. The net benefit functions for municipal and industrial agents are derived from water price-demand functions as shown in Equations (4) and (5) in the next section, for which parameters are provided in Tables S11 to S14. In addition, an agent's net benefit function will also be influenced by its level of water use efficiency improvement, as depicted in Fig. 1. A modified inverse price-demand function taking into account levels of water use efficiency improvement is shown in Equation (6). 
Fig. 1. An illustrative example of net benefit functions under different levels of water use efficiency improvement

Each general agent's decision rules are to determine whether to conserve or consume more water, and how much water in each case, based on the initial allocation this agent possesses. If an agent decides to conserve water, compensation will be provided to the agent (a "water conserver"); an agent that chooses to consume more water (a "water consumer") will have to pay a proper cost. An agent will conserve water only if the compensation value is greater than the net benefit losses from water conservation; otherwise, the agent's initial rights will be maintained. Similarly, agents will retain their initial rights unless the net benefits gained from extra water utilization cover the paid cost. In other words, no agent will receive fewer net benefits than are found in the initial allocation.

In some situations, one agent's strategy could be affected by other agents' decisions. For instance, water consumers cannot obtain extra water if there is no water conserver. Therefore, one coordinator agent should monitor behavioral changes regarding water consumption of general agents and estimate the corresponding performance of the overall system within an agent-based framework. The system performance is evaluated by employing two indicators: the aggregated system-wide net benefits and the total imbalance between compensation and cost values. For the aggregated net benefits, larger is better, whereas for the total imbalance less is better. Total imbalance is calculated by summing up all agents' incentive values as expressed by Equation (2). A positive incentive value means having compensation for water conservers; whereas for water consumers this term is negative and means a cost.

\section{Individual Optimization Problem}


An optimization problem is constructed for each agent, whereby the agent updates its water consumption based on the initial water allocation to maximize the economic returns from water usage over the planning periods. The decision variable for each agent's individual optimization problem is its level of water consumption. A deterministic situation is considered in this paper. Each general agent's main objective is to obtain economic returns over the planning periods from 1 to $\tau$ as much as possible, from either extra water utilization or compensation. For the $i$ th agent, the individual optimization problem can be formulated as follows:

$$
\begin{array}{cl}
\max _{Q \in \Omega} \sum_{t}\left(N B_{i, t}+I N C_{i, t}-C_{i, t}\right) \\
\text { subject to } & h_{i}(Q)=0 \\
& g_{i}(Q) \geq 0 \\
& Q \geq 0 .
\end{array}
$$

where $Q$ reflects water consumption; $N B_{i, t}$ represents the net benefits produced from water utilization for agent $i$ during period $t$, which is calculated by the net benefits function; INC $C_{i, t}$ refers to the incentive values for agent $i$ during period $t$; $C_{i, t}$ means the cost of achieving water conservation for agent $i$ during period $t$; and $h_{i}(Q)=0$ and $g_{i}(Q) \geq 0$ stand for the equality and non-equality local constraints for agent $i$, respectively. The symbol $\Omega$ is used to signify the feasible region of the optimization problem subject to applicable constraints.

The incentive value for each agent can be calculated by using an incentive function shown as:

$$
I N C_{i, t}=p_{i, t} *\left(Q_{i, t}^{i n i}-Q_{i, t}\right)
$$

where $p_{i, t}$ reflects the benefit or cost per unit of water conserved or consumed, respectively, for agent $i$ during period $t$; and $Q_{i, t}^{i n i}$ refers to the initial water rights for agent $i$ during period $t$. Yang 
et al. (2012) demonstrated that using water price as a signal for a water sharing problem could lead to an equilibrium status in which all available water is allocated and all users are satisfied with the allocation. In this work, a similar parameter $p_{i, t}$ reflecting the benefit or cost per unit of water transferred is utilized as a signal to guide agents in making individual decisions. When an agent utilizes less water than its initial allocation, its net benefits obtained from water utilization are reduced from its initial level, and this reduction is called net benefit losses. However, the agent will receive a compensation as expressed in Equation (2). The compensation value is affected by two factors: the value of $p_{i, t}$, which is determined by the coordinator, and the amount of water conserved $\left(Q_{i, t}^{i n i}-Q_{i, t}\right)$. For a given value of $p_{i, t}$, if a compensation value is greater than its net benefit losses, an agent chooses to conserve water. Next, this agent decides how much water to conserve by solving its own optimization problem as expressed in Equation (1). In the individual optimization problem, an agent calculates its optimal level of water consumption in order to obtain the maximum economic returns.

On the other hand, when an agent utilizes more water than its initial allocation, the net benefits obtained from water utilization are increased. However, the value in Equation (2) is negative in this case, and indicates that a charge has to be paid to get extra water. If the extra net benefits are greater than this charge, the agent selects to consume more water. Similarly, an agent solves its own optimization problem to decide how much more water to consume. Certainly, an agent may choose to neither conserve nor consume more water, which means the value in Equation (2) is equal to zero, and the cost of achieving water conservation is zero as well. Therefore, the agent will retain its initial net benefits.

The estimation of net benefit functions should consider the different characteristics of agents, and can be represented using different forms, such as the quadratic function form depicted in Fig. 
1, or derived from a water price-demand function (Wang et al. 2008; Xiao et al. 2016). The quadratic form is utilized to represent the net benefit function of agricultural agents, and is formulated as:

$$
N B_{i, t}=b_{i, t}^{0}+b_{i, t}^{1} Q_{i, t}+b_{i, t}^{2} Q_{i, t}{ }^{2}-Q_{i, t} w c_{i, t}
$$

where $b_{i, t}^{0}, b_{i, t}^{1}$, and $b_{i, t}^{2}$ represent coefficients derived from a regression model and are provided in Tables $\mathrm{S} 8$ to $\mathrm{S} 10$; and $w c_{i, t}$ is the water supply cost for water diverted to an agent, including water treatment, water distribution, and wastewater treatment costs, for which the costs for agricultural and municipal and industrial (MI) agents are provided in Table S15.

An MI agent's net benefit function is obtained by subtracting the water supply cost from the gross benefit of water use by the agent, which is derived from the water price-demand function shown as:

$$
Q_{i, t}=\alpha_{i, t} * P_{i, t}^{\beta_{i, t}}
$$

where $P_{i, t}$ reflects the price of willingness to pay to retrieve water for agent $i$ during period $t ; \alpha_{i, t}$ is a scale parameter for the water price-demand function $\left(\alpha_{i, t}>0\right)$; and $\beta_{i, t}$ is the price elasticity of demand for agent $i$ during period $t\left(\beta_{i, t}<0\right)$.

Empirical studies suggest that MI demands are relatively price inelastic (Nauges and Whittington 2010; Ghimire et al. 2015). Therefore, the price elasticity remains constant during a specific time period, but can be slightly variable for different periods. Moreover, the price of willingness to pay for additional water is going to increase as the available water decreases. When the price increases to a certain point, agents may not be willing to pay a higher price and may seek alternative sources, and this price is called "choke price" (Mahan et al. 2002). By 
introducing the concept of choke price, the inverse water price-demand function of MI agents with a constant price-elasticity is expressed as:

$$
P_{i, t}=\left\{\begin{array}{l}
P_{i, t}^{0}, \quad 0 \leq Q_{i, t} \leq Q_{i, t}^{0} \\
\left(Q_{i, t} / \alpha_{i, t}\right)^{1 / \beta_{i, t}}, \quad Q_{i, t}>Q_{i, t}^{0}
\end{array}\right.
$$

where $P_{i, t}^{0}$ and $Q_{i, t}^{0}$ refer to the choke price and the choke quantity, respectively, for agent $i$ during period $t$. The net benefits functions with efficiency improvement utilized in this paper are provided by Xiao et al. (2016), and can be derived from the modified water price-demand function with a parameter $\rho$ representing the level of efficiency improvement formulated as:

$$
\tilde{P}_{i, t}=\left\{\begin{array}{l}
P_{i, t}^{0} *(1+\rho)^{1 / 3}, \quad 0 \leq Q_{i, t} \leq Q_{i, t}^{0} \\
{\left[Q_{i, t} *(1-\rho)^{1 / 3} / \alpha_{i, t}\right]^{1 / \beta i, t}, \quad Q_{i, t}>Q_{i, t}^{0}}
\end{array}\right.
$$

Each agent seeks to maximize the economic benefits under certain hard constraints and/or soft restrictions. These constraints can be categorized into three main types: physical, policy, and system control constraints. Physical constraints generally are mass balance and capacity limit relationships for storage nodes and links. For instance, the water balance equation for a general node $k$ during period $t$ can be written as:

$$
\begin{aligned}
& S_{k, t}-S_{k, t-1}=\sum_{\left(k_{2}, k\right) \in L} Q_{k_{2}, k, t}-\sum_{\left(k, k_{1}\right) \in L} Q_{k, k_{1}, t} \\
& -\sum_{\left(k_{2}, k\right) \in L} Q_{k_{2}, k, t}^{l}+Q_{k, t}^{a}-Q_{k, t}^{c}, \quad \forall k, k_{1}, k_{2} \in K
\end{aligned}
$$

where $S_{k, t}$ is the storage volume for storage node (reservoir or aquifer) $k$ at the end of period $t$, and is equal to zero for non-storage nodes; $Q_{k_{2}, k, t}$ means the water flow from node $k_{2}$ to $k$ during period $t ; Q_{k_{2}, k, t}^{l}$ stands for water loss during transportation, due to evaporation, leakage, or seepage, from node $k_{2}$ to $k$ during period $t$, and the evaporation coefficients at reservoir nodes are 
provided in Table S7; $Q_{k, t}^{a}$ represents water adjustments at node $k$ during period $t$ as a result of local small tributaries; and $Q_{k, t}^{c}$ is used to denote water consumed at node $k$ during period $t$ needed for economic activities, for which the consumption ratios of consumptive uses are provided in Table $\mathrm{S} 6$.

In addition, capacity limits for storage nodes and links also play an important role. For example, water flow in each link towards node $k$ must not exceed the maximum capacity of the link, which can be written as:

$$
Q_{k_{1}, k, t} \leq Q_{k_{1}, k, t}^{\max }, \quad \forall\left(k_{1}, k\right) \in L
$$

or for a storage node $k$ :

$$
S_{k, t} \leq S_{k, t}^{\max }, \quad \forall k \in R E S
$$

Besides the physical constraints for each node, there are also policy and system control constraints in the consideration of social-economic or political restrictions. An obvious example is that there is normally a minimum flow requirement for links, which can be expressed as:

$$
Q_{k_{1}, k, t} \geq Q_{k_{1}, k, t}^{\min }, \quad \forall\left(k_{1}, k\right) \in L
$$

Another example from the policy point of view is that the demand for node $k$ during period $t$ $\left(Q_{k, t}^{D}\right)$ should first be provided by local tributaries, as water in local tributaries are typically accessible by local users only; then the deficit would be satisfied by water flows towards node $k$ if necessary: 


$$
\sum_{\left(k_{1}, k\right) \in L}\left(Q_{k_{1}, k, t}-Q_{k_{1}, k, t}^{l}\right) \leq \max \left\{Q_{k, t}^{D}-Q_{k, t}^{a}, \quad 0\right\}, \quad \forall\left(k_{1}, k\right) \in L
$$

Return flow is also an important part of river basin planning. In some cases, return flows from demand sites might flow towards the same node that provides water supply to the demand sites in the network, due to the simplification of real world cases. In reality, return flow is not available for use at that node; therefore, return flow must be excluded from the available supply:

$$
\sum_{\substack{\left(k, k_{1}\right) \in L \\ \text { and } \\\left(k_{1}, k\right) \in L}} Q_{k, k_{1}, t} \leq \sum_{\left(k_{2}, k\right) \in L}\left(Q_{k_{2}, k, t}-Q_{k_{2}, k, t}^{l}\right)-\sum_{\substack{\left(k, k_{1}\right) \in L \\ a n d \\\left(k_{1}, k\right) \in L}}\left(Q_{k_{1}, k, t}-Q_{k_{1}, k, t}^{l}\right)+Q_{k, t}^{a},
$$

Assuming that node $k$ is a source node, $k_{l}$ is a demand site that diverts water from and provides return flow to source node $k$, while $k_{2}$ stands for any node that has water flow, including return flow, towards the source node $k$. The right side of the equation indicates that for a time period $t$, the total effective return flow from demand site $k_{1}$ to source node $k$, represented by the summation $\sum_{\substack{\left(k, k_{1}\right) \in L \\ \text { and } \\\left(k_{1}, k \in \in L\right.}}\left(Q_{k_{1}, k, t}-Q_{k_{1}, k, t}^{l}\right)$, should be subtracted from the total effective inflow towards source node $k$, given by the term $\sum_{\left(k_{2}, k\right) \in L}\left(Q_{k_{2}, k, t}-Q_{k_{2}, k, t}^{l}\right)$. Effective flow means water flow excluding water losses during transportation. The remaining flow plus local adjustment flow are the total available water at source node $k$ during that time period.

Since all agents are a subset of general nodes, the constraints described in Equations (7) to (12) can be used to construct appropriate constraints needed for a specified agent. For instance, all equations except Equation (9) are applicable for an industrial agent.

\section{Coordination Procedure}


After specifying how each agent updates its behavior to achieve better economic returns individually, the next step is to design how they interact with one another or the environment. In general, the interactions can occur in direct or indirect ways. Direct interaction means information exchange and associated bargaining among agents, whereas indirect interaction refers to information exchange through a third party, such as a water agency or water manager acting as a coordinator. The indirect interaction procedure is adopted in this paper.

All agents communicate with the coordinator under each given value of parameter $p_{i, t}$, including receiving the value of the parameter from the coordinator and sending their levels of water consumption and overall economic returns under this given parameter back to the coordinator. When the coordinator updates the value of $p_{i, t}$, the overall economic returns agent $i$ can expect would change accordingly. Then agent $i$ would update its optimal level of water consumption in order to achieve the maximum individual overall returns. The sum of all individual agents' overall economic returns constitutes an indicator of system performance. If the sum of overall returns with the current value of $p_{i, t}$ is greater than that with previous values of $p_{i, t}$, the coordinator would increase the value of $p_{i, t}$ further until the sum cannot increase any more. Therefore, this parameter is considered as static within each iteration, but is dynamic in the overall model and serves to provide feedback among agents and the coordinator. In addition, this parameter is assumed to be the same value for all agents within each iteration, and is shortened as $p$ in the following sections.

The coordinator will monitor the behavior changes of each agent and the performance of the overall system arising from these individual alterations in behavior, and decide when to terminate the coordination. The coordination procedure controlled by the coordinator, shown as a flow chart in Fig. 2, starts by checking whether all the agents are fully satisfied during the initial 
allocation. Agent satisfaction is evaluated by calculating the ratio of water consumption to water demand during each period. When water consumption during each period is equal to demand, then this agent is fully satisfied. This metric is used for all agents. If the agents are not all fully satisfied, each one makes individual decisions on whether to conserve or consume more water and how much to conserve or consume under a given parameter $p$.

After individual decisions have been made, the coordinator will assess the overall system performance by calculating the total net benefits, total imbalance between compensation and cost values, and the net benefits increment in comparison to the results in the previous iteration. The total net benefits are compared to those of the initial allocation in the first iteration. The termination criteria of the coordinator are whether the system-wide net benefits can be further improved, and whether the total imbalance can be further decreased. If the net benefits increment is larger than a predefined tolerance value, like one thousandth of the aggregated net benefits, then it can still be improved, and another iteration with an updated value of the parameter is required. In contrast, when the system-wide net benefits cannot be further improved, there are two situations: it starts to decrease, or it remains constant. In the former situation, the coordination process is terminated immediately when the system-wide net benefits are worse off. In the latter case, under the same level of system-wide net benefits, the coordination process continues until the value of the total imbalance cannot be further decreased. When the coordination process is terminated, the results of water allocation, net benefits, compensation or cost values for all of the agents, and the aggregated results for the system can be generated and interpreted.

Fig. 2. Coordination procedure

\section{Case Study}




\section{Background Information}

In this section, the behavior of different water users in a simplified but representative basin network, reflecting an actual situation depicted in Fig. 3, is studied using the proposed agentbased model to investigate the impact of WDM. The case study is adapted from the South Saskatchewan River Basin (SSRB) problem studied by Wang et al. (2008). The SSRB is located in southern Alberta, Canada, where a semi-arid climatic condition exists. Surface water, provided by snowmelt from the Rocky Mountains, is the main source of water supply. Main water users include agriculture, municipalities, industry, and hydropower generation, in which agriculture is the largest one. A priority-based water rights system is established in the SSRB, where water licenses are required and follow the principle of "first in time, first in right." Earlier licenses are granted a higher priority over licenses issued at a later date, and license holders granted in recent years may not be permitted to withdraw water under the situation in which river flow is under a certain volume. Currently, about $75 \%$ of the licensed water is allocated to agricultural users, while new license applications are no longer approved in some water-stressed regions. Under this situation, water transfer among users is a useful tool for efficient water utilization. However, the existing legal water rights system must be respected, and consequently an initial allocation step is carried out first in this paper using a priority-based method. In addition, compensation should be given to licensed users to encourage them to conserve water.

In this paper, a simplified but representative network is designed based on the SSRB case. The network consists of typical consumptive water uses such as agricultural (A1 and A2), domestic (D1 and D2), industrial (I1 and I2), general (G1 and G2) uses, and some nonconsumptive uses like reservoirs ( $\mathrm{R} 1$ and $\mathrm{R} 2$ ), instream flow requirements ( $\mathrm{S} 1$ and $\mathrm{S} 2$ ), inflow (IN1 and IN2), outlet (O1), and junction nodes (J1 and J2). Domestic use represents water 
consumption for residential purposes. General use refers to municipal use excluding domestic use, such as water required by commercial, institutional, and other public service facilities. The number of agents for each kind is limited to two so that the responses of each agent can be clearly observed and plotted, and thereby valuable lessons can be learned. Monthly water supply data are adjusted using one eighth of the long-term average flow data in the SSRB case to reflect a particular drought year. Monthly demand data are projected in a drought year when the precipitation level is low and agriculture demand is higher than that in a normal year. The detailed water supply and demand data are provided in Tables S1 to S4, and initial storage volumes in two reservoirs are provided in Table S16 in the Supplemental Data.

Fig. 3. The network for the case study

\section{Modeling Scenarios}

The modeling time period in this case study is one year having 12 monthly time periods. As aforementioned, an initial water allocation process is performed prior to the implementation of WDM strategies to reflect social equity. The results of the initial allocation constitute a baseline case for this study in which no WDM strategies are implemented. Therefore, the impact of different strategies can be observed, analyzed, and compared.

As a general framework, the agent-based model proposed in this paper mainly focuses on the decisions of an agent regarding how much water to conserve and how much economic return can be expected. The specific strategies are not the focus of this paper. Each agent can have different measures to achieve a certain level of water conservation. For example, for agricultural agents, one can choose from drip irrigation technology, deficit irrigation, land leveling, or rescheduling irrigation to night time. Different measures may result in different levels of conservation and 
different costs. In some cases, certain technologies may have already been adopted by certain agents, and available options are dependent upon specific situations.

It is assumed that agents will choose specific cost-effective measures on their own, or will simply abandon some economic activities if the compensation is enough to cover the losses of giving them up. The cost of achieving water conservation in this model is evaluated based on per unit of water. However, this behavior is not ideal from the perspective of a water authority. As a result, a set of conservation limits is specified to reflect the maximum conservation an agent can achieve due to either technical limitations or social restrictions imposed by water authorities. More specifically, several percentages, such as $10 \%, 20 \%$, and $30 \%$, are specified as the maximum conservation an agent can achieve. The decisions of agents under different scenarios of conservation limit are investigated. Comparing their decisions under different scenarios of conservation limits also provides valuable insights for policy design.

\section{Results}

The impacts of the implementation of WDM strategies can be analyzed from two perspectives: individual and aggregated viewpoints. The individual effects on each agent and the aggregated impacts on the system are discussed in the following two sections.

\section{Individual Agent's Decisions and Economic Effects}

With the implementation of WDM strategies in a water system, the individual decisions made by different agents over different values of the parameter $p$ can first be observed. Under the scenario of a $20 \%$ conservation limit in which all of the agents can conserve at most $20 \%$ of their initial allocations, Fig. 4 depicts the agents' detailed water consumption changes under different values of the parameter $p$, and Fig. 5 shows the agents' net benefits changes. It should be noted that the 
value of net benefits shown in Fig. 5 is the sum of the net benefits gained from water utilization and compensation or cost. In fact, the patterns observed under other scenarios are similar to the results shown in Figs. 4 and 5.

Consider the case of agricultural use given as A1 in Fig. 3. The water flow towards A1 from R1 minus the water loss in the conduit is the effective inflow or water available for utilization by A1, and should be no more than A1's demand during a particular time period. By subtracting the amount of water consumed by A1, the remainder is the return flow from A1 and is available to other downstream agents. Certainly, the water flow from R1 to A1 should not exceed the maximum capacity of the conduit, but should be more than a minimum requirement scheduled by policy makers. Therefore, constraints as expressed in Equations (7), (8), (10), and (11) constitute the feasible region for $\mathrm{A} 1$ in which to search for a maximum economic return.

As can be seen in Fig. 4, two agents (A1 and A2) choose to conserve water until they reach their limit at $p=0.1$. However, their net benefits are expected to grow along with the increase in the value of the parameter $p$, mainly because of the increase of compensation value, as indicated in Fig. 5. This increase results in the growth of a total imbalance between compensation and cost values as shown by the dotted line in Fig. 6 .

On the other hand, agents G2 and I1 are willing to consume extra water, as shown in Fig. 4, and can expect more economic returns from the additional water utilization even though they have to pay a cost. As indicated in Fig. 5, the maximum economic return for both agents occurs at $p=0.1$, and thereafter starts to decrease due to the increase of cost. However, from Fig. 4, one can see that I1 reduces its water consumption starting at $p=0.7$. This implies the benefits gained from additional water utilization are not enough to cover the cost. From the bottom plot in Fig. 4, one can observe that agent G1 also prefers to consume more water but only by a slight amount. 
Other agents select to retain their initial water rights, and procure no extra net benefits. Among these agents, D1 and D2 choose not to consume more water because they are already fully satisfied during the initial allocation; therefore, their net benefits changes are omitted in Fig. 5. It should be noted that since D1, I1, and G1 share the same supply node in the network, the return flow from one agent to the supply node is not available for other agents during the same time period, as expressed by Equation (12).

There are several reasons for having the same level of water consumption for different values of parameter $p$ in Fig. 4. Firstly, for the two agricultural agents A1 and A2, they already reach their conservation limit after $p=0.1$, and their levels of water consumption remain the same for different values of parameter $p$ greater than 0.1. Secondly, for the two domestic agents D1 and D2, they already are fully satisfied during the initial allocation and they choose not to conserve water. Consequently, their levels of water consumption remain the same for all values of parameter $p$. Thirdly, for $\mathrm{I} 2$ and $\mathrm{G} 2$, they are not able to consume more water because there is no one conserving water after $p=0.1$. Finally, for I1 and G1, their levels of water consumption increase at $p=0.1$, and then keep constant until $p=0.4$, and start to reduce their water consumption after $p=0.5$. This is because the charges they have to pay are greater than their extra net benefits obtained from the extra water utilization. G1's change is very small and is difficult to see because of the scale issue.

Fig. 4. Water rights changes by agents over different values of the parameter $p$ under the scenario of a $20 \%$ conservation limit

Fig. 5. Net benefits changes by agents over different values of the parameter $p$ under the scenario of a $20 \%$ conservation limit

\section{System Performance}


The individual decisions made by agents may have different impacts on the system performance. One example is the increasing total imbalance resulting from the growing compensation to A1 and A2 even though they stop conserving water due to the conservation limit. The total imbalance of net benefits transferred is calculated by summing up all compensation values given to water conservers and all cost values paid by water consumers. A positive imbalance indicates that the compensation is larger than the cost, and can be interpreted as an infusion from outside of the system to make the strategies feasible. The infusion is expected to be as small as possible.

As affected by the increasing total imbalance, the total net benefits determined by adding up the individual net benefits of all agents are continuously growing as well, as shown by the top curve in Fig. 6. If the infusion is deducted from the total net benefits, the remainder represents the economic benefits produced by all agents in the system. From Fig. 6, one can see that the total net benefits produced by all of the agents in the system itself, excluding the infusion from outside of the system, will reach its maximum at $p=0.1$. This is the point at which the coordination process stops, and the compensation to water conservers, cost paid by water consumers, net benefits for each agent, total infusion required, and total net benefit of the system itself are determined.

Fig. 6. Total net benefits changes over different values of the parameter $p$ under the scenario of a $20 \%$ conservation limit

\section{Discussion and Insights}

An agent-based model can normally be implemented in two ways: using a packaged simulation software like AnyLogic, MASON, and NetLogo, or by custom development using high-level programming languages. The agent-based model proposed in this paper mainly consists of a set 
of individual optimization problems; it is implemented in the platform of the general algebraic modeling system $(G A M S)$ to take advantage of the key and unique features of this platform such as having extensive and efficient solvers (GAMS 2017). GAMS is a high-level modeling system for mathematical programming and optimization, and constitutes a powerful tool to solve largescale optimization problems. The individual optimization problems are coded in GAMS and solved using MINOS. In this research, the authors used a MacBook Pro laptop computer with an Intel Core i5 $2.4 \mathrm{GHz}$ CPU. It took less than 0.1 seconds to solve each of the individual optimization problems. Hence, the problem can be conveniently solved using modest computer resources.

The impact of WDM on individual agents and the overall system under one scenario is explained in the previous sections. The optimal solutions under different scenarios are compared and discussed in this section.

Fig. 7 shows the changes in water consumption whereby the bar on the left above each agent gives the agent's initial allocation. The remaining bars indicate the amount of water a given agent is going to withdraw under different scenarios. As can be seen in Fig. 7, both A1 and A2 prefer to conserve water until they reach their limits under all scenarios, since each of the bars to the right of the baseline scenario is lower than the baseline. Notice that when there is no conservation limit, both $\mathrm{A} 1$ and $\mathrm{A} 2$ relinquish all of their initial allocation, which is reflected by the absence of a bar in Fig. 7. This also demonstrates the necessity of having conservation limits because food production is still essential for agricultural agents. All other agents, except D1 and D2, tend to consume more water compared to their baselines as long as there is extra water available. G2 and I1 are the two main water consumers who utilize most of the conserved water under all scenarios, and $\mathrm{I} 2$ is not able to obtain extra water under scenarios having limits because 
of this, but is another main water consumer under the scenario of no limit, as plotted on the far right in Fig. 7. D1 and D2 are already fully satisfied during initial allocation and they would not like to conserve water as indicated by all of the bars having the same level as the baseline. The more water agricultural users conserve, the more water is available to water consumers.

In terms of an economic perspective, the net benefits for all agents, except D1 and D2, are projected to increase above the baseline, as depicted in Fig. 8. Among these agents, A1 and A2 obtain more compensation to cover their benefit loss because of utilizing less water; conserving more water implies higher compensation. Although G2 and I1 are two main water consumers under all scenarios with limits, G2 produces greater benefits with additional water than I1 does. Furthermore, I2 is also able to generate massive benefits if there is extra available water as indicated by the bar on the far right in Fig. 8. The fact that most agents are expected to gain more benefits and no one has less can encourage them to implement WDM strategies.

The implementation of WDM is also beneficial for the overall system. As can be seen in Fig. 9, the total net benefits produced by the system under all scenarios are better in comparison to the baseline case, and the higher the conservation limit, the greater the net benefits that can be produced. Even though the total imbalance is also higher under the scenario of a higher conservation limit, it is still a very small portion (less than $0.5 \%$ under all scenarios having limits) of the total net benefits produced.

In addition to the economic impact of WDM on consumptive uses, it is also important to investigate its effect on non-consumptive uses, since these uses are modeled as ecosystem agents and will only respond to the decisions of general agents. As shown by the top plot in Fig. 10, total water rights to consumptive uses are decreasing in comparison to the baseline scenario. In contrast to consumptive uses, the water flow through the two instream flow requirement nodes, 
which are labelled as S1 and S2 in the network, are increasing; higher conservation limits mean more water is available to non-consumptive uses. The increasing instream water flow could be extremely useful for maintaining environmental standards. The findings indicate that besides economic gains, benefits can also be garnered from an ecological perspective as depicted in Fig. 10.

Fig. 7. Comparison of water rights changes by agents under different scenarios

Fig. 8. Comparison of total net benefits changes by agents under different scenarios

Fig. 9. Overall net benefits in the basin from initial allocation and with WDM

Fig. 10. Comparison of water rights to consumptive and non-consumptive uses

\section{Conclusions}

In this paper, water users' responses under different conservation limits are assessed within a basin-wide agent-based framework in order to investigate the effect of WDM on individual users and the overall system. An individual optimization problem is constructed for each water user to update the level of water consumption in order to maximize its overall economic returns. Even though users' responses regarding water consumption are diversified, the overall economic returns of each user are expected to increase, which provides a positive incentive to encourage users to implement WDM strategies. Interactions among agents occur in an indirect way through a coordinator so that system performance can be improved as well. The proposed approach is applied to an illustrative case study reflecting an actual situation in southern Alberta, Canada.

The results of the case study indicate that agricultural users are more likely to conserve water, while the benefits loss from water conservation can be compensated so as to achieve a better economic return. The conserved water can be distributed to other users to produce more 
economic benefits, but a portion of the extra benefits must be transferred in order to obtain the additional water. By implementing WDM, positive incentives are provided to water conservers, and other users could also benefit. The system performance is projected to be improved as well from both economic and ecological perspectives.

The results and analyses are based on the assumption of a series of conservation limits. In fact, the results from the case study show that agricultural agents are always willing to conserve water until they reach their limits. Municipal and industrial agents also like to see higher conservation limits so that they have more water to consume and greater potential for economic returns. Therefore, it is important for policy makers to take this factor into consideration during policy design. Certainly, sub-models can be developed to estimate the technical conservation limits for different agents, and integrated into current models. This is one of the limitations of this model, and an opportunity for future work.

\section{Acknowledgements}

The authors are grateful for the constructive suggestions and comments put forward by the anonymous referees, associate editor, and editor - which enhanced the quality of the paper. The authors would also like to thank the Natural Sciences and Engineering Research Council (NSERC) of Canada for its financial support. The first author gratefully acknowledges the China Scholarship Council for providing him with a scholarship to carry out his doctoral studies (No. 201206710003).

\section{Supplemental Data}

Tables S1-S16 are available online in the ASCE Library (ascelibrary.org). 


\section{References}

Araral, E., and Wang, Y. (2013). "Water demand management: Review of literature and comparison in South-East Asia.” Int. J. Water Resour. Dev., 29(3), 434-450.

Athanasiadis, I.N., Mentes, A.K., Mitkas, P.A., and Mylopoulos, Y.A. (2005). "A hybrid agentbased model for estimating residential water demand." Simulation, 81(3), 175-187.

Baumann, D.D., Boland, J.J., and Hanemann, W.M. (1997). Urban water demand management and planning, McGraw-Hill, New York.

Berglund, E.Z. (2015). "Using agent-based modeling for water resources planning and management." J. Water Resour. Plann. Manage., 141(11), 10.1061/(ASCE)WR.1943$5452.0000544,04015025$.

Blanke, A., Rozelle, S., Lohmar, B., Wang, J., and Huang, J. (2007). "Water saving technology and saving water in China." Agric. Water Manage., 87(2), 139-150.

Bristow, M., Fang, L., and Hipel, K.W. (2014). "Agent-based modeling of competitive and cooperative behavior under conflict.” IEEE Trans. Syst. Man Cybern: Syst., 44(7), 834-850.

Brooks, D.B. (2006). “An operational definition of water demand management.” Inter. J. Water Resour. Dev., 22(4), 521-528.

Brooks, D.B., and Brandes, O.M. (2011). "Why a water soft path, why now and what then?" Inter. J. Water Resour. Dev., 27(02), 315-344.

Butler, D., and Memon, F.A. (Eds). (2006). Water demand management, IWA Publishing, London.

Christian-Smith, J., Cooley, H., and Gleick, P.H. (2012). "Potential water savings associated with agricultural water efficiency improvements: A case study of California, USA." Water Policy, 14(2), 194-213. 
Chu, J., Wang, C., Chen, J., and Wang, H. (2009). “Agent-based residential water use behavior simulation and policy implications: A case-study in Beijing city." Water Resour. Manage., 23(15), 3267-3295.

GAMS (General Algebraic Modeling System). (2017). “GAMS - Introduction.” 〈https://www.gams.com/products/introduction/〉 (May 19, 2017).

Ghimire, M., Boyer, T.A., Chung, C., and Moss, J.Q. (2015). "Estimation of residential water demand under uniform volumetric water pricing." J. Water Resour. Plann. Manage., 142(2), 10.1061/(ASCE)WR.1943-5452.0000580, 04015054.

Giacomoni, M.H., Kanta, L., and Zechman, E.M. (2013). “Complex adaptive systems approach to simulate the sustainability of water resources and urbanization." J. Water Resour. Plann. Manage., 139(5), 554-564.

Giuliani, M., and Castelletti, A. (2013). "Assessing the value of cooperation and information exchange in large water resources systems by agent-based optimization." Water Resour. Res., 49(7), 3912-3926.

Giuliani, M., Castelletti, A., Amigoni, F., and Cai, X. (2014). "Multiagent systems and distributed constraint reasoning for regulatory mechanism design in water management." $J$. Water Resour. Plann. Manage., 141(4), 10.1061/(ASCE)WR.1943-5452.0000463, 04014068.

Gleick, P.H. (2003). "Global freshwater resources: Soft-path solutions for the $21^{\text {st }}$ century." Science, 302(5650), 1524-1528.

Gleick, P.H., and Heberger, M. (2014). "Water conflict chronology." In: The world's water, volume 8: the biennial report on freshwater resources, 173-219. Island Press/Center for Resource Economics, Washington, D.C. 
Kampragou, E., Lekkas, D.F., and Assimacopoulos, D. (2011). "Water demand management: Implementation principles and indicative case studies.” Water Environ. J., 25(4), 466-476.

Kanta, L., and Zechman, E. (2013). “Complex adaptive systems framework to assess supply-side and demand-side management for urban water resources." J. Water Resour. Plann. Manage., 140(1), 75-85.

Kindler, J. (2010). "Water demand management." In: A review of selected hydrology topics to support bank operations, 35-49, HEF (Hydrology Expert Facility) Technical Report 1, World Bank, Washington, D.C.

Leflaive, X., Witmer, M., Martin-Hurtado, R., Bakker, M., Kram, T., Bouwman, L., Visser, H., Bouwman, A., Hilderink, H., and Kim, K. (2012). "Water.” In: OECD environmental outlook to 2050: The consequences of inaction, OECD (Organization for Economic Co-operation and Development) Publishing, Paris. 〈http://dx.doi.org/10.1787/env_outlook-2012-8-en〉(July 14, 2016).

Maas, T. (2003). "What the experts think: Understanding urban water demand management in Canada.” POLIS Project on Ecological Governance, University of Victoria, Victoria, BC.

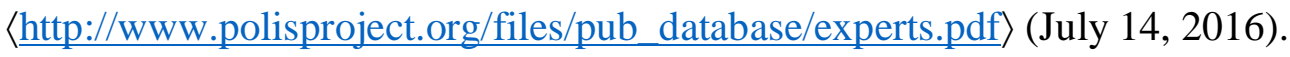

Macal, C.M., and North, M.J. (2010). “Tutorial on agent-based modelling and simulation.” J. Simul., 4(3), 151-162.

Mahan, R.C., Horbulyk, T.M., and Rowse, J.G. (2002). "Market mechanisms and the efficient allocation of surface water resources in southern Alberta." Socio-Econ. Plann. Sci., 36(1), 2549. 
Mohamed, A.S., and Savenije, H.H.G. (2000). "Water demand management: Positive incentives, negative incentives or quota regulation?" Phys. Chem. Earth Part B: Hydrol. Oceans Atmos., 25(3), 251-258.

Nauges, C. and Whittington, D. (2010). "Estimation of water demand in developing countries: An overview." The World Bank Res. Obser., 25(2), 263-294.

Olmstead, S.M. (2014). "Climate change adaptation and water resource management: A review of the literature." Energ. Econ., 46, 500-509.

Olmstead, S.M., and Stavins, R.N. (2009). "Comparing price and nonprice approaches to urban water conservation." Water Resour. Res., 45(4), W04301.

Pahl-Wostl, C. (2002). "Agent based simulation in integrated assessment and resources management." Integrated assessment and decision support, Proc. 1st Biennial Meeting Int. Environ. Modelling and Software Society, A. Rizzoli, and T. Jakeman, eds., Vol 2, 239-250.

Pahl-Wostl, C. (2003). "The importance of the human dimension in integrated assessment models and processes: Actor based analysis and modeling approaches." Proc. Modelling and Simulation Society of Australia and New Zealand, MODSIM, 465-472.

Renzetti, S. (2002). The economics of water demands. Kluwer Academic, Boston, MA.

Savenije, H.H., and Van Der Zaag, P. (2002). "Water as an economic good and demand management paradigms with pitfalls.” Water Int., 27(1), 98-104.

Scheierling, S.M., Loomis, J.B., and Young, R.A. (2006). "Irrigation water demand: A metaanalysis of price elasticities." Water Resour. Res., 42(1), W01411.

Schlüter, M., and Pahl-Wostl, C. (2007). "Mechanisms of resilience in common-pool resource management systems: An agent-based model of water use in a river basin.” Ecol. Soc., 12(2), 4. 
Smith, N.J., McDonald, G.W., and Murray, C.F. (2015). "The costs and benefits of water demand management: Evidence from New Zealand.” Water Environ. J., 29(2), 180-189.

Tate, D.M. (1989). "Water demand management in Canada: A review and assessment." Canadian Water Resour. J., 14(4), 71-82.

Wang, L., Fang, L., and Hipel, K.W. (2007). "Mathematical programming approaches for modeling water rights allocation." J. Water Resour. Plann. Manage., 133(1), 10.1061/(ASCE)0733-9496(2007)133:1(50), 50-59.

Wang, L., Fang, L., and Hipel, K.W. (2008). "Basin-wide cooperative water resources allocation." Eur. J. Oper. Res., 190(3), 798-817.

Wolf, A. (Ed). (2002). Conflict prevention and resolution in water systems, Elgar, Cheltenham, UK.

WWAP (World Water Assessment Programme). (2015). The United Nations world water development report 2015: Water for a sustainable world. United Nations Educational, $\begin{array}{llll}\text { Scientific and Cultural } & \text { Organization }\end{array}$ 〈http://www.unesco.org/new/en/natural-sciences/environment/water/wwap/wwdr/2015-water-

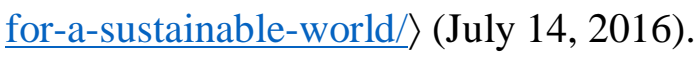

Xiao, Y., Hipel, K.W., and Fang L. (2016). "Incorporating water demand management into a cooperative water allocation framework." Water Resour. Manage., 30(9), 2997-3012.

Yang, Y.C.E., Cai, X., and Stipanović, D.M. (2009). "A decentralized optimization algorithm for multiagent system-based watershed management." Water Resour. Res., 45(8), W08430.

Yang, Y.C.E., Zhao, J., and Cai, X. (2012). "Decentralized optimization method for water allocation management in the Yellow river basin." J. Water Resour. Plann. Manage., 138(4), 10.1061/(ASCE)WR.1943-5452.0000199, 313-325. 


\section{Appendix}

Table A1. Structure of the agent-based model

\begin{tabular}{|c|c|c|}
\hline Agent Type & Attributes & Decision Rules \\
\hline General agent & $\begin{array}{l}\text { 1. Level of water } \\
\text { consumption } \\
\text { 2. Level of net } \\
\text { benefits represented } \\
\text { by net benefits } \\
\text { functions }\end{array}$ & $\begin{array}{l}\text { 1. After receiving a value of parameter given by } \\
\text { the coordinator, each agent calculates the net } \\
\text { benefits generated from water utilization and } \\
\text { compensation or cost value. } \\
\text { 2. An agent chooses to conserve water only if the } \\
\text { compensation value is greater than the net } \\
\text { benefit losses, or to consume more water if the } \\
\text { net benefits produced from extra water } \\
\text { utilization are more than enough to cover the } \\
\text { cost charged. } \\
\text { An agent adjusts the level of water consumption } \\
\text { to maximize its individual total economic } \\
\text { returns by solving an individual optimization } \\
\text { problem. }\end{array}$ \\
\hline $\begin{array}{l}\text { Ecosystem } \\
\text { agent }\end{array}$ & $\begin{array}{l}\text { 1. Level of water } \\
\text { consumption }\end{array}$ & 1. Respond to the actions of general agents. \\
\hline $\begin{array}{l}\text { Coordinator } \\
\text { agent }\end{array}$ & $\begin{array}{l}\text { 1. Overall net benefits } \\
\text { 2. Total imbalance } \\
\text { value }\end{array}$ & $\begin{array}{l}\text { 1. For each given value of a parameter, monitor } \\
\text { the decisions of individual agents and calculate } \\
\text { the system-wide overall net benefits and total } \\
\text { imbalance between the compensation and cost } \\
\text { values. } \\
\text { 2. Update the value of the parameter until the } \\
\text { system-wide net benefits cannot be improved } \\
\text { and the total imbalance value cannot be } \\
\text { decreased. }\end{array}$ \\
\hline
\end{tabular}

